\title{
Socio-cultural Barriers to Girls Education in Malakand District of Pakistan
}

\author{
Sunbal Shah, Hussain Ali* and Saba Gul \\ Department of Sociology, Abdul Wali Khan University Mardan-Pakistan \\ Department of Sociology, Abdul Wali Khan University Mardan-Pakistan \\ Department of International Relations, Abdul Wali Khan University Mardan-Pakistan
}

KEYWORDS Early Marriage. Girl's Education. Pakistan. Patriarchy. Socio-cultural Barriers. Subordinate Position

\begin{abstract}
Girls' education is important for women empowerment and socio-economic development, which is largely ignored in the study area due to socio-cultural factors. The objective of the study is to investigate various socio-cultural factors, which hinder girls' access to higher secondary education in Malakand, Khyber Pakhtunkhwa in Pakistan. Researchers used a quantitative research approach with cross-sectional research design, and data was randomly collected through self-administered questionnaire from 336 presently registered girl students in higher secondary education institutions in the projected area. In the manuscript descriptive univariate statistics with simple frequency and percentages were used while the Pearson Correlation test was applied to draw the strength of association between girls' accessibility to the education institutions and socio-cultural barriers in accessing education institutions. The Pearson Correlation result shows that sons' education is preferred over daughters' education in the study area. Results indicated that early girl marriage restricts girls' access to getting formal education. Civil society and government should raise awareness on girl education.
\end{abstract}

\section{INTRODUCTION}

Access to education is one of the basic human rights, which are recognised by the United Nations and other international agencies. In the $21^{\text {st }}$ century it is acknowledged that enrolled girls' number in education is higher as compared to prior years while in developing world girls' education right is still denied and the number of total illiterate adult women is $2 / 3$ (two-third) in the world (Somani 2017). The Pakistan Education Statistics Report (2018) indicated that forty-four percent of girls and fifty-six percent of boys are enrolled in the educational institutions of Pakistan. In Pakistan the gender discrimination is observed at all the levels of education. It is statistically shown that at the primary stage only forty-five percent girls are enrolled. Similarly, at secondary level of education the ratio is forty-two percent of girls' enrolment and fifty-eight percent is the ratio of boys' enrolment (GoP 2018). The inequality is highly noticed at the level of HSE where the ratio of enrolled boys is sixty-two percent while only thirty-nine percent of girl students are registered. It is also shown in the Pakistan Education Statistics Report, that there are a total of 6.29 million school children at the

"Address for correspondence:

E-mail: hussainali@awkum.edu.pk higher secondary level in the country, and among the out-of-school children, 3,204,111 (3.20 million) are girls that are out of school at the age of 15-16 years. According to the Pakistan Education Statistics Report (2018), nearly fifty percent $(49.0 \%)$ of girls are not enrolled in formal schooling (from class one (primary) to class $12^{\text {th }}$ (higher secondary education). In Khyber Pakhtunkhwa province of Pakistan nearly fifty percent $(49.0 \%)$ female students are out of educational institutes at the age of five to sixteen (5-16) years (GoP 2018).

Many authors revealed that major barriers in girls' access to higher secondary education are due to poor institutional performance and lack of facilities (Mehmood et al. 2018; Naz et al. 2012). In many research studies it is emphasised that girls' educational institutions are less in number as compared to boys' educational institutions (Naz et al. 2013). Mostly the girls' educational institutions are far away from one another with no transportation facilities. It is also shown that facilities in girls' educational institutions are lacking due to low priority given to girls' education (Suleman et al. 2018; Alam 2017).

The authors identified that very few research studies highlighted the socio-cultural and socioeconomic barriers that hinder accessibility of girls to HSE in the country. Many research studies highlighted that girls are socialised to perform the household activities and there is very limited 
scope for girls to get higher education (Alam 2017). It is statistically shown in research studies that early marriage among girls is a socially approved practice and it is considered a sign of shame for parents if their daughter remains at home without being married. Early marriage among girls not only causes maternal and infant mortality, but also it is one of the major social barriers for girls in accessing and getting higher secondary education (DeJong 2000). In patriarchal societies women are treated as subordinates with very minimal decision-making authority related to their education (Bhatti and Jeffery 2012). In developing countries women are strongly discouraged to participate in public sphere activities and decision-making. It is revealed in many studies that in traditional societies, women's outer mobility is restricted and allowed only when the male family members permit it. It is highlighted that due to outer mobility restriction for women, they are discouraged to access educational institutions (Asif et al. 2021). In such societies, boys' education is preferred over girls' education with the perception that men are the earning hand of the family in later stages of life while women are the property of in-laws in later stages of life (Raj et al. 2014). According to the feminist perspective, women are oppressed due to their gender and gender role. In traditional and male dominant societies women are compelled to please their male family members and when a girl reaches the age of 15 years her parents wish to arrange her marriage instead of sending her for attaining higher education (Naz et al. 2013). A woman is socialised about her role as nurse and caring for the other members of family from a very early age. It is also highlighted in various studies that women have to listen to their male family members and obey their orders and instructions in all walks of life. In traditional societies, women involvement in decision-making is strongly discouraged and they are bound to perform the activities as per the wishes of their male family members (DeJong 2000). In many studies it is stated that women are oppressed in decision making related to their education, mate selection, reproductive practices and use of family planning methods and contraception (Alam 2017).

One of the black American African feminists, Patricia Hill Collins, presented a theory of the interlock system of oppression. She argued that women in all societies are oppressed due to their gender, class and race. She further explained that one of the fundamental factors of oppression is gender, which prevails around the world, and women are oppressed due to their gender in both developed and developing countries (Collins 1990). She argues that due to her gender a woman is restricted from getting her fundamental rights such as access to health facilities, education, decent employment, political participation and other rights explained in international treaties. She argues that the other two factors of oppression, race and class, greatly contribute to gender as the main factor of oppression. It is discussed that if a woman suffers due to her gender and she also belongs to a lower class and ethnic minority it further makes the situation worse for a woman in any society. It is revealed in many research studies that besides the lack of institutional facilities and schools, the major barriers to women accessing and getting higher secondary education in Pakistan is lack of family support and restriction on women education and outer mobility (Naz et al. 2013).

\section{Objectives}

The major objective of the study is to investigate the socio-cultural factors that influence girls' education in Malakand, Pakistan.

\section{METHODOLOGY}

\section{Study Design}

Researchers used the quantitative research approach and cross-sectional research design to collect the statistical responses (Bethlehem 1999). In the study area there were 15 higher secondary education institutions.

\section{Sample Population}

Five schools and colleges were selected among 15 from the two Tehsils of Sama Ranizai (Dargai) and Swat Ranizai (Batkhela). The total strength of currently enrolled girl students was 2,505 among the selected schools and colleges in which 336 girl students were selected via the Sekaran standard formula for sample selection.

\section{Sampling Technique and Tool of Data Collection}

The responses of selected samples were collected through simple random sampling techniques.

J Soc Sci, 70(1-3): 1-7 (2022) 
Researchers developed and pre-tested a selfadministered questionnaire. In the questionnaire, authors covered the socio-demographic variables and socio-cultural factors as a barrier to girl education. The research questions in the study were:

1. What are the girls restricted from for getting higher secondary education due to patriarchy and men's dominance?

2. How can early marriage and restriction on outer mobility discourage girls from accessing higher secondary education?

3. How does women's gender and gender role hinder them from getting higher secondary education?

In the present manuscript researchers first conducted a consultative meeting with the District Education Office (women) and an orientation session was held with the officials to share the objective of the study. During orientation sessions the district education officials were requested to issue directives to the higher secondary education institutions to facilitate researchers in filling the questionnaires and collection of data. The district education department informed all the secondary education institutions to facilitate the research team.

In the $1^{\text {st }}$ week of March 2020, the quantitative data collection began. Unfortunately, due to the outbreak of COVID-19, the government declared a lockdown in the projected research area. The government of Pakistan announced SOPs to avoid gatherings and meeting with people, and encouraged people to stay at home. All the organisations including educational institutes were closed down. Unfortunately, the data collection process was stopped for several months because of the COVID-19 pandemic, which spread widely so the researchers stayed at home during these months.

At the end of the third week of the September 2020, the government re-opened higher secondary education institutes after following strict safety precautions against COVID-19. After the re-opening of colleges and schools, researchers began visiting the targeted education institutions for the collection of quantitative data from selected women respondents.

Researchers went along with the World Health Organisation and government of Pakistan's safety guidelines given for the COVID-19 pandemic while visiting education institutes (schools and colleges). Researchers used gloves and protective masks to visit selected schools and colleges. Researchers used hand antiseptic before, then after starting to gather data and after the collection of data from the women student respondents' researchers used hand antiseptic again. Hand sanitisers and masks were also distributed among the respondents.

\section{Analysis}

Researchers used SPSS for statistical analysis. Researchers applied descriptive statistics to draw the frequency and percentages of the respondents while inferential statistics with Pearson Correlation test was applied to draw the strength and direction of the association in independent and dependent variables.

\section{Ethical Consideration}

In the present manuscript researchers followed the ethical consideration and verbal consent of all the respondents before filling the questionnaire (Neuman and Robson 2014). The researchers also conducted an orientation session with the principals and head teachers, and after their verbal consent, the responses of the currently enrolled girls were recorded. Researchers ensured that their personal information would be kept confidential and the responses would be used to improve the opportunities for girls in accessing higher education institutions.

\section{RESULTS}

Table 1 described the socio-demographic characteristics of the enrolled women students in HSE. Among the total 336 respondents, seventy-four percent of the female student respondents were in the age category of eighteen to twenty (18 to 20) years, and 25.6 percent of the respondents were in the age category of fifteen to seventeen (15 to 17) years. Table 1 described the registered class of the female student respondents. Among the total 336 women student respondents, 54.8 percent of the respondents were enrolled in $2^{\text {nd }}$ year (second year) of intermediate and the remaining less than half of the respondents $(45.2 \%)$ of the women enrolled students were enrolled in $1^{\text {st }}$ year (first year). Table 1 also described the respondents' marital status. Of the total 336 enrolled women respondents, 77.1 percent of the respondents were single, fourteen percent of the enrolled women students were married, and 8.9 percent respondents were engaged. In the study area early marriage among girls is a

J Soc Sci, 70(1-3): 1-7 (2022) 
Table 1: Socio-demographic characteristics of the women students currently enrolled in higher secondary education institutions in Malakand $(\mathrm{N}=\mathbf{3 3 6})$

\begin{tabular}{|c|c|c|}
\hline Characteristics (Students) & $F$ & (\%) \\
\hline \multicolumn{3}{|c|}{ Age of the Respondents in Complete Years } \\
\hline $15-17$ & 86 & $(25.6)$ \\
\hline $18-20$ & 250 & (74.4) \\
\hline \multicolumn{3}{|c|}{ Enrolled Class of the Respondent } \\
\hline 1 st year & 152 & $(45.2)$ \\
\hline 2nd year & 184 & (54.8) \\
\hline \multicolumn{3}{|c|}{ Marital Status of the Respondents } \\
\hline Married & 47 & $(14.0)$ \\
\hline Unmarried & 259 & (77.1) \\
\hline Any other & 30 & (8.9) \\
\hline \multicolumn{3}{|l|}{ Area of Residence } \\
\hline Urban & 158 & $(47.0)$ \\
\hline Rural & 178 & $(53.0)$ \\
\hline
\end{tabular}

socially approved practice, therefore most of the families engage or settle the marriage of their girl children during the schooling age. Table 1 shows the residential areas of the women students. In total, of the 336 enrolled women student respondents, fifty-three percent of the respondents were residing in rural areas while the remaining, nearly fifty percent $(47 \%)$ of the respondents, were residing in the city zones (Table 1 ). In the study, the researchers covered the respondents from both the rural and urban residences to draw the correlation of sociocultural factors influence on women education in both the areas.

In the Pearson Correlation (Table 2) test, the correlation between sons' preferences over women education is fifteen percent and the association is highly significant at the level of 0.01 . It is also shown in Table 2 that the sons' preference evicts daughters from access to HSE at eighty percent and the association is found at 0.01. Due to the patriarchal structure of society and male dominancy in the study area, parents prefer their sons' education because they are the earning hands of the family. It is also observed that parents enrolled their son in better education systems while they ignore their daughters' education. Parents perceived their daughters as members of her future husbands' family so there is no return from a daughter's education to her parents' family.

In Table 2 the association between girls' access to HSE and child marriage among girls is twentysix percent and the association is significant at the level of 0.01 . Table 2 discussed the relationship

Table 2: Socio-cultural barriers to women in accessing higher secondary education in district Malakand ( $\mathrm{N}=336)$

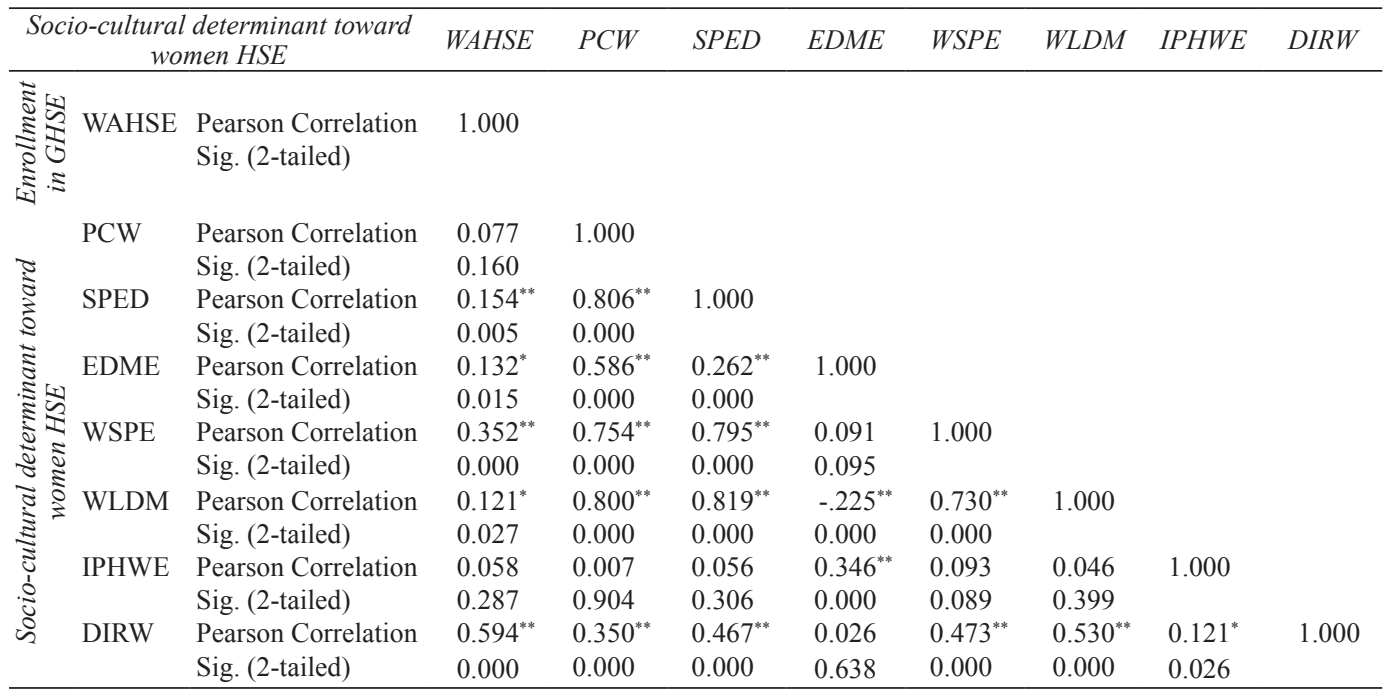

Denotation: $\boldsymbol{H S E}=$ Higher secondary education, $\boldsymbol{G H S E}=$ Government higher secondary education, $\boldsymbol{W A H S E}=$ women are allowed to get higher secondary education, $\boldsymbol{P C W}=$ patriarchy confine women, $\boldsymbol{S P E D}=$ Sons' preference evicts daughter from education, $\boldsymbol{E D M E}=$ early marriage deterrent to women higher secondary education, $\boldsymbol{W S P E}=$ women subordinate position affect women education, $\boldsymbol{W L D M = w o m e n ~ l i m i t e d ~ d e c i s i o n ~ m a k i n g ~ a f f e c t ~ w o m e n ~ e d u c a t i o n , ~ I P H W E = i l l i t e r a t e ~ p e o p l e ~}$ hinder women education, $\mathbf{D I R} \boldsymbol{W}=$ distance from institutions restrict women

${ }^{* *}$ Correlation is significant at the 0.01 level (2-tailed).

"Correlation is significant at the 0.05 level (2-tailed).

J Soc Sci, 70(1-3): 1-7 (2022) 
between girls' access to HSE and subordinate position of women at seventy-nine percent as highly significant at the level of 0.01 . In the study area, child marriage among girls is a socially approved practice because a daughter would move to husband's family after marriage, and therefore their education is considered an extra burden on the parents' family. The parents prefer early marriage of their daughters, which restricts women's access to education.

Table 2 discussed that the association between girls' access to HSE and women's minimal decision-making authority related to her education is seventy-three percent and the association is found to be highly significant at the level of 0.01. In the study area, women decision-making is discouraged due to their illiteracy and financial dependency on their male family members. A girl's choice and decision making power in getting formal education is highly discouraged. The decision about girls' education and choice of an education institution is completely the matter of her parents and elder brother. It is the choice of her parents to decide about her education and they usually prefer girls to attain religious education in Madarsa. Table 2 shows the relationship between girls' access to HSE and illiteracy among family members is thirty-four percent and the association is found significant at the level of 0.05 . The study is conducted in a tribal district where most of the parents are illiterate. The illiterate parents first of all do not enjoy the birth of a daughter and with the birth of a daughter they start thinking about her marriage. Parents are not willing to send their daughters to get formal education, as due to their illiteracy they consider their daughter's education to be useless. Table 2 shared that the relationship between women's access to HSE and distance from education institutions is fifty-nine percent and the association is found highly significant at the level of 0.01 . The Pearson Correlation between women's access to HSE and the patriarchal structure of society confining girls to the domestic sphere has no significant relationship (Table 2). The study area is located in the mountains where the population is scattered. The schools and other educational institutions are located in the city or locations where the population is in high number due to which the girls living at long distances are unable to continue their education.

\section{DISCUSSION}

The researchers stated that women's access to higher secondary education is not only restricted due to supply side gaps, rather the socio-cultural factors also hinder women access to education (Erdemir and Wu 2021). It is stated in the study that due to the patriarchal structure of society women have no choice to access education institutions without the consent and permission of their male family members (Bereng and Mutekwe 2021). It is also revealed in other studies that in traditional societies men are dominant in decision making related to women's education, health and marriage settlement (Asif et al. 2021). It is discussed in many research studies that women are treated as subordinate due to their gender and their mobility is restricted due to their gender role. It is discussed that in patriarchal societies men define the sphere and role in the spheres. It is revealed that men are the decision makers in both the public and private sphere while women are confined to the domestic sphere with very minimal decision-making authority particularly related to household purchase and caring of the children (Cerrato and Cifre 2018).

In the manuscript researchers highlighted that in the study area sons' education is preferred as compared to a daughter's education due to the latter's gender and gender role. It is also stated in many other studies that the desire for a male child is not only the priority of parents, rather their education is preferred in traditional and patriarchal societies as well. It is perceived that sons are the earning hand of the family and they are the actors to care for the parents in their older age (Yadav et al. 2020). On the other side, girls are considered the permanent members of their future in-laws' family and they have no economic contribution to the parents' family. In patriarchal families it is the general perception that men are the contributor to livelihood activities while women are dependent on men's earning (Atreya et al. 2020).

The researchers stated that one of the socially approved practices in patriarchal society is early marriage among girls. The early marriage among girls hinders women's access to higher secondary education in the study area. It is also discussed in other studies that in traditional and male dominant societies, parents prefer the early marriage of their girl because they are considered an economic

J Soc Sci, 70(1-3): 1-7 (2022) 
burden on the family (Paul 2019; Mustafa et al. 2017). In traditional society it is a general customary practice that women of older age have less probability to marry than women in early age. The researchers stated that early marriage among girls is ratified in the patriarchal structure of society. The early marriage among girls hinders women's access to HSE in the projected area. Furthermore, it is discussed in previous studies that in traditional and male dominant societies parents prefer the early marriage of their girl because they are considered an economic burden on the family (Paul 2019).

The researchers revealed that women are subordinates in the family and due to their subordinate position, their outer mobility is restricted. Their enrolment in schooling is not encouraged at higher secondary education level. Many other researchers revealed that women are oppressed in the patriarchal society and due to their gender they are restricted from getting formal education. Women in the family are socialised to perform the role of nursing and caring at home (McAllum et al. 2021; Katz-Wise et al. 2010). Due to women's subordinate status in household affairs their decision-making is very minimal in their access to education, decent employment and healthcare services. Women are dependent on the men's decision making in household affairs. It is stated in many other studies that women are not allowed to decide about the access to education of their daughter and other women in the joint family structure. In traditional and male dominated societies men are the key decision-makers in both domestic and public sphere affairs (Snyder 2020). The decision related to women education and mate selection is purely dependent on the wellbeing of the male family members in patriarchal society. It is also stated in the present manuscript that women are restricted from getting education due to their parents' illiteracy. It is discussed in other similar research studies that in developing countries most of the parents are illiterate and have no formal education, and due to this reason they have no knowledge about the importance of girl education (Ibrahim et al. 2020). Most of the parents are unaware about the role of an educated woman in the individual, community and national socioeconomic development. The researchers stated that one of the potential obstacles to women's education is the distance from education institutions. Due to long distance, the parents are reluctant to allow their daughters to get formal education. It is revealed in other studies that in developing countries most of the families are living in rural areas where the schools are located far away from each other. Due to long distance and no transportation facility the parents prefer their daughter's religious education to be completed in the local areas and early marriage is encouraged due to no formal education (Joshi and Ahir 2020; Jamal 2016).

\section{CONCLUSION}

The present study concluded that sociocultural factors, including a son's education preference over a daughter's, are significantly correlated with barriers to a girl's education in the study area. In the study area family structure is patriarchal and men are the key decision makers due to which a girl's education is discouraged. It is concluded that in the study area early marriage among girls is a socially approved practice, which is a social barrier to girl's education.

\section{RECOMMENDATIONS}

It is recommended that girls should be involved in the decision-making process related to household affairs, her education and mate selection. It is also recommended that early marriage among girls should be discouraged at the societal level and the government should develop rational intervention strategies to stop early marriages among women, which play a negative role in a girl's access to education and decent jobs. The civil society organisations are required to promote civic education and highlight the importance of a girl's education for her family and society.

\section{LIMITATIONS}

In the present manuscript researchers only focused on barriers to women accessing higher secondary education and the quantitative research design was used. Due to the COVID-19 pandemic and limited resources the study is conducted only in one tribal district in the province of Khyber Pakhtunkhwa in Pakistan.

\section{ACKNOWLEDGMENTS}

The researchers acknowledge the cooperation and support of the District Education Department, Malakand, and the principal and teaching staff of

J Soc Sci, 70(1-3): 1-7 (2022) 
the targeted education institutions in the study district. The researchers acknowledge the cooperation of the currently enrolled girl students who actively participated in the study.

\section{REFERENCES}

Alam S 2017. Female education: The facilitating and hindering factors regarding female education in Gilgit-Baltistan context of Pakistan. intWOJDE, 6: 35-52.

Asif MF, Pervaiz Z, Afridi JR, Abid G, Lassi ZS 2021. Role of husband's attitude towards the usage of contraceptives for unmet need of family planning among married women of reproductive age in Pakistan. BMC Women's Health, 21: 1-7.

Atreya A, Nepal S, Arjun KC 2020. Alcohol provoked fatherson assault: A case report from Nepal. Birat Journal of Health Sciences, 5: 1119-1121.

Bereng M, Mutekwe E 2021. Examining the manifestations and ramifications of the patriarchal ideology in female-led schools in the North West Province of South Africa. Perspectives in Education, 39: 191-207.

Bethlehem J 1999. Cross-sectional Research. Research Methodology in the Social, Behavioural and Life Sciences. Delhi: SAGE Publications India Pvt Ltd.

Bhatti F, Jeffery R 2012. Girls' schooling and transition to marriage and motherhood: exploring the pathways to young women's reproductive agency in Pakistan. Comp. Educ, 48: 149-166.

Cerrato J, Cifre E 2018. Gender inequality in household chores and work-family conflict. Front Psychol, 9: 1-11.

Collins HP 1990. BlackFeminist Thought: Knowledge, Consciousness, and the Politics of Empowerment. New York: Routledge.

DeJong GF 2000. Expectations, gender, and norms in migration decision-making. Popul Stud, 54: 307-319.

Erdemir B, Wu Q 2021. An examination of Turkish and Chinese equity-related barriers to higher education admissions from the capabilities perspective. Asia Pacific Education Review, 1-16.

GoP 2018. Pakistan Education Statistics Report- Annual Status of Education Report Pakistan, Lahore: ASER Pakistan.

Ibrahim ZL, Khan A, Bin Ramli J 2020. Cultural and socioeconomic status factors affecting female education in Sokoto State, Northern Nigeria: Implication for counselling. Universal Journal of Educational Research, 8: 124-128.

JamalA2016. Why he Won't send his daughter to school-Barriers to girls' education in Northwest Pakistan: A qualitative Delphi study of Pashtun men. SAGE Open, 6: 1-14.

Joshi KM, Ahir KV 2020. Women in higher education in India: Historical influences, contemporary narratives, and the way ahead. In: C Fontanini, KM Joshi, S Paivandi (Eds.): International Perspectives on Gender and Higher Education. Bingley BD16 1WA, United Kingdom: Emerald Publishing Limited, pp. 171-191.

Katz-Wise SL, Priess HA, Hyde JS 2010. Gender-role attitudes and behavior across the transition to parenthood. Dev Psychol, 46: $18-28$.

McAllum K, Simpson ML, Unson C, Fox S, Kilpatrick K 2021. The socialization of unpaid family caregivers: A scoping review. Research on Aging, 01640275211005092.

Mehmood S, Chong L, Hussain M 2018. Female's higher education in Pakistan: An analysis of socio-economic and cultural challenges. ASSRJ, 5: 379-397.

Mustafa M, Zakar R, Zakar MZ, Chaudhry A, Nasrullah M 2017. Under-five child mortality and morbidity associated with consanguineous child marriage in Pakistan: Retrospective analysis using Pakistan demographic and health surveys, 1990-91, 2006-07, 2012-13. Matern Child Health J, 21: 1095-1104.

Naz A, Daraz U, Khan W, Sheikh I 2013. Physical and infrastructural obstacles to women's education in Khyber Pakhtunkhuwa Pakistan. FWU J Soc Sci, 7: 139-145

Naz A, Daraz U, Khan W, Hussain M, Khan Q 2012. The dormancy of empowerment: An analytical study of various impediments to women's education in Khyber Pakhtunkhwa Province of Pakistan. SSRN Electronic Journal, 2: 78-87.

Neuman WL, Robson K 2014. Basics of Social Research. Toronto: Pearson Canada.

Paul P 2019. Effects of education and poverty on the prevalence of girl child marriage in India: A district-level analysis. Child Youth Serv Rev, 100: 16-21.

Raj A, McDougal L, Silverman JG, Rusch ML 2014. Crosssectional time series analysis of associations between education and girl child marriage in Bangladesh, India, Nepal and Pakistan, 1991-2011. PloS One, 9: 1-9.

Snyder KA 2020. Gender ideology, and the domestic and public domains among the Iraqw. In: Henrietta Moore, Todd Sanders, Bwire Kaare (Eds.): Those Who Play with Fire. Routledge, pp. 225-253.

Somani T 2017. Importance of educating girls for the overall development of society: A global perspective. JERAP, 7: 25-39.

Suleman Q, Hussain I, Jumani NB 2018. Occupational stress among secondary school heads: A gender based comparative study. JoEED, 5: 240-258.

Yadav AK, Anand A, Singh RA, Jungari S 2020. Sex composition and son preference in India and major states: Evidence from the National Family Health Survey-4 (2015-16). Clinical Epidemiology and Global Health, 8: 1140-1146.

Paper received for publication in August, 2021

Paper accepted for publication in January, 2022

J Soc Sci, 70(1-3): 1-7 (2022) 